\title{
Positron lifetime measurements in polyethylene under different conditions
}

\author{
G. BRAUER, Th. DANIEL* ${ }^{*}$ W. FAUST ${ }^{* *}$, Z. MICHNO ${ }^{* * *}$ and H. SCHNEIDER ${ }^{* *}$ \\ Research Centre Rossendorf Inc., WIP Project, P.O. Box 510119, 01314 Dresden, Germany \\ * Phys. Chem. Institut \\ ** Strahlenzentrum, Univ. Giessen, 35392 Giessen, Germany \\ *** Technical University Opole, Poland
}

\begin{abstract}
Positron lifetime measurements were performed on polyethylene probes of different denstities under various atmospheric conditions within a $\gamma$-dose range from 0 kGy up to 1460 kGy. We present here experiments non destroying the sample. Four components could be resolved in each iffetime spectrum; the components consist each of a lifetime $\gamma$ and an intensity $I$. In the dose range investigated the behaviour of the lifetime parameters of the longest1 ived $\left(\tau_{4}, I_{4}\right)$ and the second long-11ved $\left(\tau_{\xi}, I_{3}\right)$ component, respectively, could be explained by the $\gamma$-induced recristallisation and the creation of hydroperoxides. The average free valume as a function of the dose may be calculated out of the lifetime of the fourth component $\left(\tau_{4}\right)$.
\end{abstract}

Introduction

Among organic solids, polyethylene (PE) repeatedly has been subject by different positron annihilation techniques $/ 1-7 /$. Of the four resolved positron 1 ifetimes the longest one $\left(\tau_{4} \simeq 2,5\right.$ ns) is associated with ortho-positronium (aPs), the shortest one $\left(r_{7} \approx 0.1\right.$ ns) is - at least partially - associated with para-positronium (p-Ps), and an intermediate one ( $\tau_{\mp}=0.3$ ns) with free positrons not forming positronium (Ps). The origin of the third component ( $\tau_{3}=1$ ns) has been under debate, i.e. it should be due to either a positron or o-Ps bound to a molecule. However, at present it seems that there exists more evidence in favor of the latter interpretation of $\tau_{3} / 8 /$.

Changes of $P E$ materials properties during irradiation have been studied by positron annihilation and could be well correlated with the results of other methods /9-12/. Thereby a general real-time state-of-matter description of poIymers during irradiation has been suggested.

Here we present experiments on high density PE for doses up to 1460 kGy to study the irradiation induced effects non-destructive by the positron lifetime technique.

Results and Discussion

PE (Lupolen 4261 A, from BASF Ludwigshafen, Germany) with a density of 0.942 $\mathrm{g} \mathrm{cm}^{-3}$ and a crystallinity of $59 \%$ was used $/ 13 /$ as starting material for $\gamma-1 r^{-}$ radiations with the ${ }^{\circ} \mathrm{C}$ Co source at the Strahlenzentrum of the Universitat Giessen. Separate sample pairs $(50 \mathrm{~mm} \times 50 \mathrm{~mm}$ x $5 \mathrm{~mm})$ were cut from larger plates $\left(0.5 \mathrm{~m}^{2}\right)$ for each irradiation taking place in air at room temperature with a dose rate of $0.54 \mathrm{kGy} \mathrm{h}^{-1}$. Positron lifetime measurements (with a 22 Ha-source 


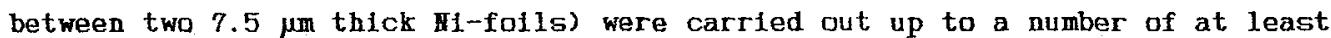
more then $1 \times 10^{6}$ integral counts. The measurements were performed with a positron 1 ifetime spectrometer based on BaFz-scintillators (Harshow Cheme, Vermelskirchen, Germany) and XP2020Q (Valvo, Hamburg, Germany) photomitipliers having a time resolution of about 400 ps FryM. The final analysis was performed with four components and the constraints (i) $3 I_{1}=I_{3}+I_{4}$, and (i1) e.g. $\tau_{1}=120 \mathrm{ps}$. The 1 ffetimes and intensities of the components vary with the degree of Irradiation /13/.

The longest-lived component $\left(\tau_{4}, I_{4}\right)$ shows the pick-off annihilation of ortho-positronium atoms (o-Ps) primarily in the amorphous regions (in the free volumes).

Due to the $\gamma$-irradiation in the polymer chains there may be produced radicals by klcking off H-atoms /14/. Subsequently different chemical reactions (recristallisation, creating of hydroperoxides, crosslinking, degradation) are induced. Immediately after the beginning of irradiation the oxygen, dissolved in polyethylene, may be bound forming hydroperoxides at the polymer chains in the amorphous regions. Hore oxygen for this reaction is supplied by diffusing from the air into the sample /15/.

By lacreasing the dose, cross-1inking of the polyethylene /15/ together with disarranged folding in the amorphous regions is induced, and consequently the created hydroperoxides are screened off by polymer chalns. At doses higher than $500 \mathrm{kGy}$ the degradiation prevails /15/ (preferentially in the amorphous regions of the polyethylene), and furtheron disarranged folding takes place. But now previously screened off hydroperoxides get avallable for reactions.

Because of the disarranged folding of the polymer chains in the amorphous regions there is induced a recristallisation /3/. Consequently the fraction of amorphous regions is reduced with Increasing dose. This effect can be seen by the decreasing of $I_{4} / 5 /$ and on the behaviour of the reciprocal density $\rho^{-1}$. It is found that $p^{-1}$ (measured by BASF) correlates with changes of the intensity $I_{4}$ as a function of the applied $\gamma$-dose (fig. 1).

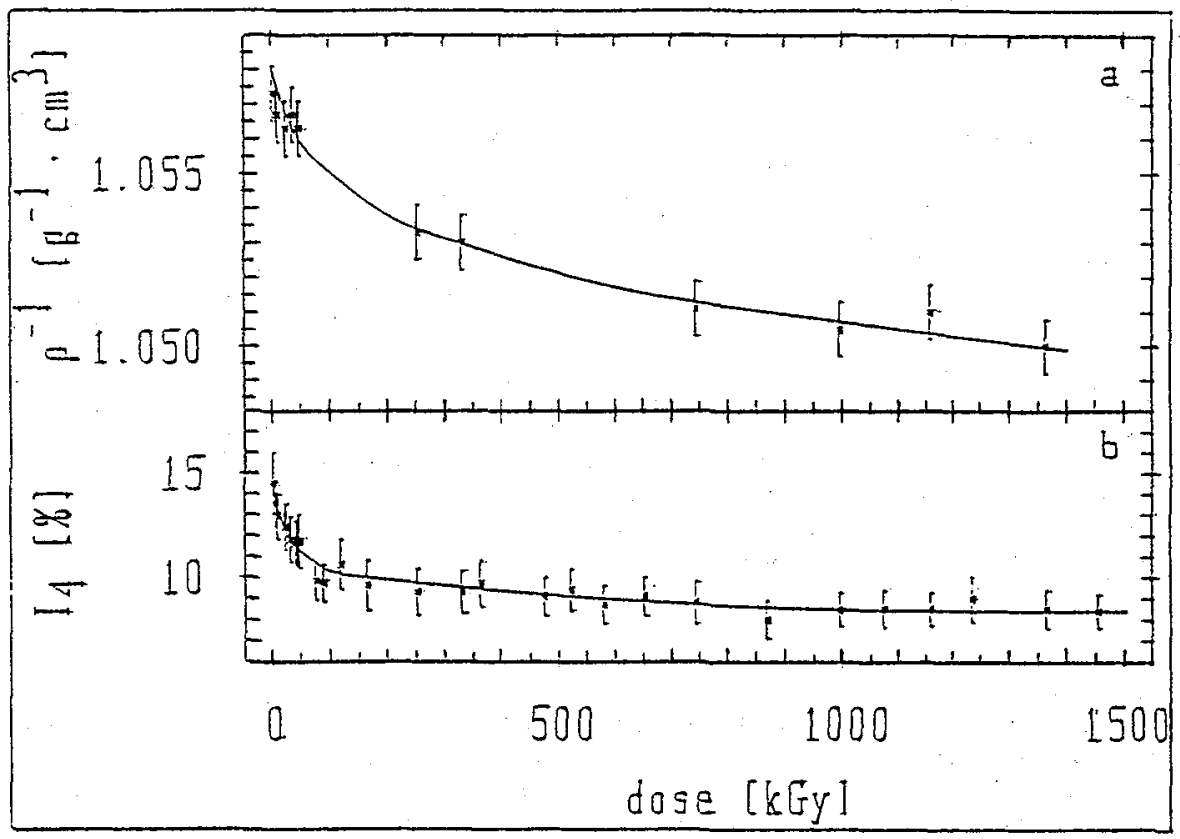

Fig. 1. Behaviour of the reciprocal denstty $p^{-1}$ (a) and of the Intensity IA (b) (relative units) as a function of the ${ }^{\circ} \mathrm{Co}-\gamma$-dose. 
The iffetime of the fourth component $\left(\tau_{4}\right)$ depends on the free volume (i.e. from the crystalliaity $/ 7 /, / 13 /)$. In $/ 16 /$ there is given a model to calculate the 11 fetime of o-Ps atoms 1 nside the free volume $\left(V=4 \pi R_{\infty} 2 / 3 ; R_{0}=\right.$ Free volume radius).

To decide on the reproduclbility of results (c.p. /17/) and possible aging effects of unradiated materials "old" (1990) and "new" (1992) Lupolen samples have been studied. F.g. with a time resolution of about 215 ps and different statistics /18/, a constraint free analysis of all spectra gave the averages collected in Table 1.

Table 1. Global averages of the components $(\tau[\mathrm{ps}]$, I [\%] $) / 13 /$

$\begin{array}{lllllll} & r_{1} & T_{2} & r_{3} & T_{4} & I_{3} & T_{4} \\ \text { "O1d" } & 85 \pm 10 & 307 \pm 5 & 1100 \pm 22 & 2620 \pm 33 & 12.46 \pm 0.30 & 16.15 \pm 0.38 \\ \text { " HBW" } & 80 \pm 15 & 308 \pm 5 & 955 \pm 16 & 2581 \pm 10 & 12.14 \pm 0.35 & 16.18 \pm 0.15\end{array}$

It is found $/ 18 /$ that the counting statistics has no significant influence on the final evaluations if more than $3 \times 10^{5}$ counts are collected. The $\tau_{1}$ values given are possibly a little too short compared to the p-Ps lifetime (125 ps) but not unreasonable. Except for the $\tau_{3}$ value there are no changes in the measurable parameters due to the age of the samples.

Acknowledgements

One of us (Z,X.) particlpated in this work as a scholar of the VE-Heraeusstiftung, Hanau. This work was supported by the Deutsche Forschungsgemeinschaft, Bann-Bad Godesberg. Ve are thankful for providing the polyethylene to the BASF, the analysis programmes to Dr. B. Levay (POSFIT), Karlruhe, and to P.D. Dr. H. Sormann (POSGAOSS), Graz, Austria.

\section{References}

/1/ K. Eldrup, In: Positron Solld-State Physics, Proc. Internat. School of Physics "Fnrico Fermi", Course LXXXIII, Varenna on Lake Com 1981, Ed. V. Brandt, 644, Horth Holland, Amsterdan (1983).

/2/ P. Kindl, Habil. thesls, university of Graz (1983).

/3/ P. K1ndl, G, Reiter, phys. stat. sol. (a) 104, 707 (1987).

/4/ G. Reiter, Ph D thesis, university of Graz (1987).

/5/ J. Ch. Abbe, G. Duplatre, J. Serna, in: Positron Annihilation, L. Dortkens-Vanpraet, H. Dorlkens, D. Segers (Eds.), 796, World Sclentiflc, Singapore (1989).

f6/ A. Badia, J. Ch. Abbé, G. Duplâtre, ICPA-9, 9th Int. Conf. on Positron Andillation, D10, Szombathely, August, 26th-31ti, (1991).

$17 /$ F.H.J. Maurer and K. Welander, J. Adheston Sc1. Technol. Vol. 5, Mo. 6, pp. 425-437 (1991).

18/ A. Cornaz, J. Brunner, E. Cartier, In: Positron Annihtlation, L. Dorlkens-Vanpraet, K. Dorlkens, D. Segers (Eds.), 793, Vorld Scientific, Singapore (1989).

f9f G. Brauer, V. Hertle, A.G. Balogh, phys. stat. sol. (a) 105, K7 (1988).

$110 /$ G. Brauer, . Hertle, E. Miller, T. Tzscheutschler, Radiat. Phys. Chem. 33. 307 (1989).

$111 /$ G. Brauer, W. Hertle, 'Kunststoffe' 78, 424 (1988).

$/ 12 /$ G. Brauer, Y. Hertle, B. Miller, W. Tzscheutschler, Report ZfK-678, Zentralinstitut für Kernforschung Rossendorf (1989).

/13/ V. Faust, $\mathrm{Ph} \mathrm{D}$ thesis, untversity of Giessen (1991).

/14/ E. Köhnlein; in 'Kunststoffe', 65th year, no, 9 (1975).

/15/ H.U. Volgt, F, Wizcnerowlcz; Energlewtrtschaft1. Tagesfragen (ET) 11 524 (1974).

110/ Y.C. Jean; Hicrochem. J. 42, 72 (1990); Nucl. Instr. and Heth. B56/37, 615 (1991).

$117 /$ L. Dorikens-Vanpraet, D. Segers, H. Dor1kens, Appl. Phys. 23, 149 (1980).

/18/6. Duplatre, private commulcation (1993). 